\title{
Is the Push for Gender Sensitive Research Advancing the SDG Agenda of Leaving No One Behind?
}

Logan Cochrane and Nitya Rao

\begin{abstract}
Following decades of advocacy, collecting sex disaggregated data and conducting gender analyses have become an expected aspect of research in development studies. We strongly support this shift, yet it has focused attention upon one manifestation of inequality. We explore five dimensions of inequality, as expressed in health metrics in Ethiopia, to highlight diverse manifestations of inequalities. We call for a broader approach to understanding inequalities and how the simultaneous experience of multiple, intersecting inequalities, is greater than their sum. This shift is essential to support the 'leave no one behind' agenda of the Sustainable Development Goals.
\end{abstract}

Keywords: Social inequalities, social differentiation, gender, health, Ethiopia

\section{Introduction}

Since the 1970s, greater attention has been paid to the role of gender in development studies research. There are academic journals devoted to the subject, targeting both practitioners (Gender \& Development) and academics (Gender and Society, Feminist Studies, amongst others); and gender is the theme of annual reports from international institutions such as the World Economic Forum, the World Bank and the United Nations. Research donors are requiring, or strongly requesting, that researchers collect sex disaggregated data and conduct gender-based analyses (ACIAR, 2011; DFID, 2008; Gates Foundation, 2017; CGIAR, 2017; Duchesne, Tannenbaum and Einstein, 2017). Researchers are also calling for gender to be a necessary unit of analysis (e.g. Morchain et al, 2015; Njuki and Sanginga, 2013; Sweetman, 2001). We strongly support this trend.

As researchers, we recognize that gender analysis involves a relational approach, based on the social construction of gender in particular space-time contexts (Rao, 2017). It is characterised by an exploration of the 'intersecting power relations of race, class, gender, sexuality, age, ability and nation' (Collins, 2010: 8), amongst others. In interacting with research donors, we have therefore found ourselves speaking against a narrow approach, focusing primarily on sex-disaggregation of data, as limiting our understanding of wider social processes through which multiple, intersecting inequalities are reproduced and perpetuated (Crenshaw, 1989, Walby, 2007). While gender certainly cross-cuts other forms of inequality, women, or for that matter men, are not homogenous groups. Devoting resources to one component, usually sex-disaggregation, in data collection and analyses, results in fewer studies exploring the interactions of gender with other forms of social difference, or the multiple layers of social inequalities people experience in their lived realities. While this is not a new argument, we would like to emphasise that being relational, some intersections may be more salient than others at particular historical moments. Uncovering these patterns of interdependence, the fluidity of connections within and across categories, is central to understanding the continuities and changes in social inequalities (Collins, 2010: 23).

As we progress into the era of the 2030 Sustainable Development Agenda, understanding the diverse drivers and manifestations of social inequality and difference are crucial. Deepening inequalities 
threaten, amongst other challenges, the democratic values that form the very basis of modern society (Piketty, 2014). This is already visible in the rise of religious fundamentalist movements, identity-based politics, various forms of violence and crime, and threats to multi-culturalism and tolerance across the world. If not urgently addressed, the 'price of inequality' can be high (Stiglitz, 2013). Addressing inequality, and the trends of it increasing, are a fundamental requirement if we are to move toward achieving the ambitious objectives of the Sustainable Development Goals (SDGs), and the 'Leave No One Behind' objective (UN, 2016; UNDP, 2016). Making progress from the reductions envisaged in the Millennium Development Goals (MDGs) to the elimination of exclusions of the SDGs will require new approaches to research and practice (Cochrane and Thornton, under review).

In this paper we explore the questions about identities and statuses, including gender, and social inequalities more broadly, through a case study of health indicators in Ethiopia. The selection was pragmatic (available data) and out of familiarity (shared research area of authors). The objective is not to highlight specific data points, but to explore the diverse manifestations of social inequalities and the ways in which they interact and multiply, to shape particular wellbeing outcomes. We draw on the growing research on intersectionality to conclude that while data collection and analyses of sex and gender are essential, they ought not to predominate considerations of other forms and experiences of social inequality. A more open approach to inequality and difference could play a key role in ensuring that the needs of everyone are appropriately considered and adequately addressed.

\section{Methods}

The analyses in this article are restricted to one country and one sector within it: Ethiopia and Health. The data was drawn from the World Health Organization's (WHO) Health Equity Assessment Toolkit (HEAT), using data from the 2015 update (the most recent at the time of analysis in March, 2017; WHO, 2016). We analyze sixteen infant and child health metrics across different dimensions of potential social differentiation: gender, location, wealth, education and regional-states / geopolitics. Ethiopia was not selected based on prior knowledge about which country dataset would make a strong case, but rather our familiarity and past work in the country as well as the availability of data sets from 2000, 2005 and 2011. The WHO data set has other indicators, which we did not explore such as substance abuse and road safety, as well as cases and deaths due to communicable and non-communicable diseases. Future studies may analyze or integrate these additional data sets to further explore the ways in which social inequalities, vulnerability and risk manifest themselves. We do not determine the causes of social differentiation in infant and child health in Ethiopia, rather we use these indicators as a means to explore the diverse manifestations of social inequalities.

We have clustered the sixteen infant and child health metrics into two broad categories: (1) measures that are greatly affected by service provision and access, but not limited to that, such as immunization and the provision of rehydration salts when required, and (2) complex measures with multiple potential causes, such as stunting and mortality. In making this grouping, we recognize that the first cluster of measures is also complex, and access is just one of many factors affecting coverage. The clustering, however, is an attempt to differentiate those indicators that are representative of healthcare service provision (cluster 1 ) and those that are more reflective of a health status (cluster 2 ). They help us explore the different enablers and barriers for change, and the ways in which social identity and status mediate outcomes. Table 2 outlines the sixteen indicators, the two clusters and the abbreviations used throughout this work. 
Table 1. Sixteen WHO HEAT infant and child health measures utilized

\begin{tabular}{|l|l|l|}
\hline$\#$ & Indicator & Abbreviation \\
\hline & Cluster 1 & \\
\hline 1 & BCG immunization coverage among one-year-olds (\%) & BCG \\
\hline 2 & DTP3 immunization coverage among one-year-olds (\%) & DTP3 \\
\hline 3 & Full immunization coverage among one-year-olds (\%) & FULL \\
\hline 4 & Measles immunization coverage among one-year-olds (\%) & MEA \\
\hline 5 & Polio immunization coverage among one-year-olds (\%) & POL \\
\hline 6 & Children aged <5 years with diarrhoea receiving oral rehydration salts (\%) & ORS \\
\hline 7 & Children aged 6-59 months who received vitamin A supplementation (\%) & VAS \\
\hline & Cluster 2 & \\
\hline 8 & Infant mortality rate (deaths per 1000 live births) & IMR \\
\hline 9 & Neonatal mortality rate (deaths per 1000 live births) & NMR \\
\hline 10 & Under-five mortality rate (deaths per 1000 live births) & U5M \\
\hline 11 & Underweight prevalence in children aged $<3$ years $(\%)$ & UP3 \\
\hline 12 & Underweight prevalence in children aged $<5$ years (\%) & UP5 \\
\hline 13 & Stunting prevalence in children aged $<3$ years (\%) & SP3 \\
\hline 14 & Stunting prevalence in children aged $<5$ years (\%) & SP5 \\
\hline 15 & Wasting prevalence in children aged $<3$ years $(\%)$ & WP3 \\
\hline 16 & Wasting prevalence in children aged $<5$ years (\%) & WP5 \\
\hline
\end{tabular}

For each of the sixteen indicators, we analyze five different potential means - males and females, urban and rural, economic status by quintile, education status by attainment, and regional-state location through which social inequalities might be expressed. The selection of these five domains was due to the availability of data, collected using individual surveys. To enable a consistent assessment, we only used indicators that had data for all domains, and excluded those that did not, meaning that many gender-specific services, such as antenatal care coverage and births attended by skilled health personnel, were excluded because comparisons of sex could not be made. While we are cognizant that gender does not equate with sex, the data available within the WHO HEAT database utilized the binary categories, posing a serious limitation to our argument on advancing beyond sex disaggregated data. Where possible, we point to the ways in which disparities and inequalities are multiplied, through an intersection of some of these variables. However, the WHO HEAT database does not allow for reanalysis of the original survey data in order to specify where the layering exists, and thus explorations are probabilistic in nature and supported by qualitative data.

Taking this narrow approach to analyze a broad question necessitates that we emphasize the limitations of this article. The analysis of this data set is exploratory - we did not set forth to challenge any single type of analysis, but to assess how different elements of social difference affect wellbeing, in this case, health outcomes. The impetus of this analysis was in response to our experience that research donor agencies are requiring researchers to collect and analyze sex disaggregated data, and in doing so are potentially limiting the critical approach taken to understanding social differentiation, and more broadly, social inequalities. The use of one country calls for caution in drawing upon the results of this work and making generalizations. Ethiopia has specific socio-cultural, political, economic and demographic factors that must be considered. Similarly, the focus upon infant and child health indicators does not necessarily 
mean that social differentiation in other sectors, even within Ethiopia, will be the same - be that in agriculture, education or finance. It is hoped that the analyses that follow encourage similar critical investigations into other sectors and countries.

We recognize that there are limitations in utilizing the data from the WHO HEAT database. The data is drawn from governmental sources, the national Demographic and Health Surveys (DHS). For each of the reports $(2000,2005,2011)$ the Central Statistics Authority of Ethiopia utilized an American consulting firm to support the DHS reports, which were co-published with UNFPA and USAID. While the data is widely used, there are normative issues, as well as methodological and data challenges that should be considered (Carletto, Jollife and Banerjee, 2015; Jerven, 2013). Several authors have argued that indicators are rapidly multiplying as tools for promoting a variety of social justice and social reform strategies, yet the deployment of statistical measures tend to depoliticise rights, replacing political debate with technical expertise. The measures convey knowledge that is decontextualized and ahistorical, apart from reflecting elite perspectives (Merry, 2011: 584). Ethiopia in particular has heightened concerns of the politicization of data (Cochrane and Yeshtila, 2018; Bekele, 2017) and the invisibility or selected visibility of social inequalities in datasets. It is also a country where political contexts are rarely taken into consideration in health research (Ostebo, Cogburn and Mandani, 2017), despite the negative trends on individual rights and freedoms. While cognizant of the need for improved data and different kinds of data, and the problems with statistical measures, we nevertheless utilize the WHO HEAT database in this article, not to measure trends or disparities, but rather to illustrate the workings of inequality across groups and regions (Hosseinpoor et al, 2016).

\section{Sex and gender matter!}

The push for sex disaggregated data was put on the global agenda in the early 1970s, when feminist academics and development practitioners realised that the trickle-down approach to development was not working, benefits were not equally shared, nor were equal opportunities available to men and women across classes and social groups. Esther Boserup's classic text, Women's Role in Economic Development (1970), even though critiqued, pointed to the invisibility of women's work in agriculture. It made clear that while women were fully productive workers, this was not visible to the world of development practitioners and researchers. The first International Women's Conference held in Mexico in 1975, and the International Women's Decade that followed, sought to address this problem through the systematic collection of sex-disaggregated data (Razavi and Miller, 1995). That such data collection is commonplace today is an achievement of this early advocacy. The Fourth World Women's Conference, held in Beijing in 1995, celebrated women's solidarity and the progress made over the past two decades, but also pointed to areas where data was still inadequate, urging the development community, activists and academics, to develop alternate modelling frameworks to fully account for women's work. In particular, there was a call to make visible the "unequal distribution of remunerated and unremunerated work between women and men" (Rao, 2018 forthcoming).

Over the two decades since Beijing, key indicators reveal progress towards greater equality between men and women, whether in terms of secondary education, longevity, decline in fertility, or participation in public life (Molyneux and Razavi, 2005; Cornwall and Edwards, 2015). Yet new challenges have arisen, reflected in the informalization of work, cuts in welfare services and budgets, a resurgence of identity politics and rise in conflict, which have made it imperative to address inequalities and discrimination beyond gender, building alliances for the protection of human rights and social 
justice more broadly (Molyneux and Razavi, 2005; Cornwall and Edwards, 2015). If women's intersecting identities of class, race, ethnicity and religion, amongst others, are not taken on board, the gains made could begin to erode (Crenshaw, 1989).

\section{Ethiopian context: Infant and child health}

While many of the infant and child health indicators for Ethiopia continue to be at unacceptable levels (Table 2), the trend for the majority of indicators between 2000 and 2011 suggest that health outcomes are positive (e.g. health is improving). It is worth reiterating that these figures and trends are questionable based on quality and politicization of data (see methods), as well as external factors, such as the improved reporting after 2004-2005 in tandem with the health extension program. Taking these improvements as stated by the government, the results of this paper demonstrate that the benefits of improved national infant and child health are not equally benefiting everyone, and it is the factors of differentiation that the following analyses highlight, starting with sex-based discrimination.

Table 2. Trend for health indicators over time

\begin{tabular}{|l|l|c|c|c|c|}
\hline$\#$ & Indicator & 2000: National & 2005: National & 2011: National & Trend \\
\hline & Cluster 1 & & & & + \\
\hline 1 & BCG & 45.6 & 60.4 & 66.3 & + \\
\hline 2 & DTP3 & 21.2 & 32.7 & 37.0 & + \\
\hline 3 & FULL & 14.5 & 20.8 & 24.6 & + \\
\hline 4 & MEA & 26.6 & 34.9 & 55.7 & + \\
\hline 5 & POL & 35.0 & 45.8 & 45.1 & + \\
\hline 6 & ORS & 13.1 & 19.9 & 26.3 & + \\
\hline 7 & VAS & 59.9 & 46.1 & 53.1 & + \\
\hline & Cluster 2 & & & 73.7 & + \\
\hline 8 & IMR & 112.8 & 80.2 & 42.6 & + \\
\hline 9 & NMR & 58.2 & 60.6 & 26.0 & + \\
\hline 10 & U5M & 187.7 & 132.4 & 28.8 & + \\
\hline 11 & UP3 & 38.7 & 29.4 & 38.5 & + \\
\hline 12 & UP5 & 41.1 & 33.2 & 44.3 & + \\
\hline 13 & SP3 & 52.7 & 45.9 & 9.9 & + \\
\hline 14 & SP5 & 57.5 & 50.9 & 12.4 & + \\
\hline 15 & WP3 & 15.6 & 12.2 & & + \\
\hline 16 & WP5 & 12.5 & & & + \\
\hline
\end{tabular}

Disaggregating the sixteen health indicators by sex, it is evident that disparities exist, but they are not manifested in the ways that might be assumed (Table 3). In the first cluster of indicators, related to service provision, there was a strong male bias in 2000 and 2005, however in 2011, for most indicators this trend had reversed and there was a bias toward females (with the exception of oral rehydration therapy). This is a remarkable shift in a relatively short period of time, with some indicators, like BCG immunization coverage moving almost ten percentage points. During this period, the MDGs placed a strong emphasis on addressing gender inequalities, especially through a reduction of maternal mortality by 75 per cent and achieving universal access to reproductive health (MDG 5) (http://www.un.org/millenniumgoals/maternal.shtml). The result was greater funding for addressing 
gender disparities, especially female disadvantage, and a stronger emphasis on reporting sex disaggregated data. By 2011, it appears that this was so successful that the female bias of 2011 was in some cases larger than the male bias of 2000 (e.g. DTP3 immunization, full immunization, polio immunization and vitamin A supplementation). The first cluster demonstrates significant change, and in many cases reversal, in a short period of time.

Table 3. Sex disaggregated data for 16 health indicators (red positive, blue negative)

\begin{tabular}{|l|l|c|c|c|}
\hline$\#$ & Indicator & 2000: Male Bias & 2005: Male bias & 2011: Male Bias \\
\hline & Cluster 1 & & & -4.1 \\
\hline 1 & BCG & +5.6 & +6.9 & -4.3 \\
\hline 2 & DTP3 & +3.4 & +4.5 & -2.9 \\
\hline 3 & FULL & +0.9 & +3.9 & 0.0 \\
\hline 4 & MEA & +1.7 & +3.2 & -4.5 \\
\hline 5 & POL & +2.8 & +2.7 & +4.5 \\
\hline 6 & ORS & +0.4 & +3.0 & -1.7 \\
\hline 7 & VAS & +0.2 & -0.4 & $\mathbf{2 0 1 1 : ~ F e m a l e ~ B i a s ~}$ \\
\hline & Cluster 2 & & & +21.6 \\
\hline$\#$ & Indicator & 2000: Female Bias & $\mathbf{2 0 0 5 : ~ F e m a l e ~ b i a s ~}$ & +16.8 \\
\hline 8 & IMR & +23.2 & +21.4 & +23.4 \\
\hline 9 & NMR & +18.4 & +14.7 & +6.2 \\
\hline 10 & U5M & +18.8 & +20.2 & +3.5 \\
\hline 11 & UP3 & +8.3 & +5.9 & +5.4 \\
\hline 12 & UP5 & +4.6 & +1.7 & +3.6 \\
\hline 13 & SP3 & +6.5 & +5.9 & +4.9 \\
\hline 14 & SP5 & +3.3 & +3.0 & +2.9 \\
\hline 15 & WP3 & +4.5 & +3.8 & +2.4 \\
\hline 16 & WP5 & +2.6 & & \\
\hline
\end{tabular}

Counter to what might be expected from the literature on sex-based and gender-based discrimination, the health status indicators in the second cluster (of mortality, underweight, stunting and wasting rates) all show positive female bias. In other words, the rate of infant mortality is higher for males than females, as are all other indicators for all three reporting periods (2000, 2005 and 2011). Considering the changes in the first cluster, the stability of these disparities is remarkable. In the WHO's "Analytical Summary" for Ethiopia, the differences between male and female mortality are not mentioned (WHO, 2017), though some site-specific studies in Ethiopia have found higher rates of male infant mortality (Asefa, Drewett and Tessema, 2002; Weldearegawi et al, 2015). However, not all studies have found this to be the case (e.g. Deribew, Tessema and Girma, 2007). In fact, higher rates of male infant mortality are common throughout the world, the traditional explanations for them provided by genetics and biology. Pongou $(2013 ; 2015)$ refined this by analyzing environmental contexts as well as preconception and prenatal conditions, emphasizing the role of social processes and environmental influences alongside biology and genetics.

This analysis of health indicators shows how disparities exist for male and female children in their healthcare coverage and health statuses. This information should be collected, further analyses are required to identify who these children are, as well as on-going monitoring, in order to ensure equitable 
outcomes. Given the MDG push for gender equality, action has been taken to correct male bias, but similar action, unfortunately, seems lacking in addressing male disadvantage.

\section{Social inequalities beyond gender}

Obtaining data that allows for disaggregation by sex is what many donors are demanding of research, and the above analysis provided important insights into how disparities are not static, but change over time, and what disparities manifest amidst broad positive trends of improved national health. In our experience doing research, however, we encountered disparities other than those driven by sex, and thus the following section explores four additional dimensions for analyzing social differentiation. These expressions draw attention to the bigger picture of inequality, and its multiple drivers, and suggest that entry points for addressing vulnerability and marginalisation may lie in policies targeted at women, but equally in broad-based improvements in health service provisioning and improvements in its quality. As already noted, a limitation of our data is the inability to re-analyse using multiple criteria simultaneously.

\section{Rural-Urban}

Concern about rural disparities is not new (Chambers, 1983; 1997; 2006), nor is it new in Ethiopia (e.g. Asefa, Drewett and Tessema, 2002; CSA, 1994). The fact that this disparity has been identified, however, does not mean it deserves less attention. It is through comparative analysis, viewed over more than a decade, that the extent and trends of rural-urban disparities can be contextualized.

Table 4. Rural-Urban disaggregated data for 16 health indicators (red positive)

\begin{tabular}{|l|l|c|c|c|}
\hline$\#$ & Indicator & 2000: Urban Bias & 2005: Urban bias & 2011: Urban Bias \\
\hline & Cluster 1 & & & \\
\hline 1 & BCG & +28.0 & +25.6 & +17.8 \\
\hline 2 & DTP3 & +33.8 & +37.0 & +29.0 \\
\hline 3 & FULL & +30.9 & +31.3 & +27.8 \\
\hline 4 & MEA & +40.7 & +33.2 & +27.8 \\
\hline 5 & POL & +28.3 & +26.7 & +25.6 \\
\hline 6 & ORS & +37.0 & +27.2 & +20.5 \\
\hline 7 & VAS & +18.0 & +18.3 & +4.3 \\
\hline & Cluster 2 & & & $\mathbf{2 0 1 1 :}$ Urban Bias \\
\hline$\#$ & Indicator & $\mathbf{2 0 0 0 :}$ Urban Bias & $\mathbf{2 0 0 5 :}$ Urban bias & +16.1 \\
\hline 8 & IMR & +18.5 & +15.5 & +1.99 \\
\hline 9 & NMR & +13.0 & +6.7 & +31.9 \\
\hline 10 & U5M & +43.0 & +36.7 & +12.0 \\
\hline 11 & UP3 & +15.1 & +14.9 & +13.8 \\
\hline 12 & UP5 & +14.0 & +17.1 & +10.7 \\
\hline 13 & SP3 & +13.9 & +17.5 & +14.9 \\
\hline 14 & SP5 & +11.2 & +16.5 & +6.3 \\
\hline 15 & WP3 & +5.1 & +3.8 & +4.9 \\
\hline 16 & WP5 & +5.6 & +4.1 & \\
\hline
\end{tabular}


As shown in Table 4, the urban bias is consistent across all sixteen indicators. A key difference between the sex disaggregation and the rural-urban disaggregation is between cluster 1 and cluster 2 . In other words, availability and access play an important role. For the 2011 sex-disaggregated data, the first cluster of indicators had the largest disparity of +/- 4.5 percentage points (both for male and female disparities), while in 2011 urban bias reached a high of +29 percentage points (for DTP3 immunization). Unlike the case of sex disparities, there were no indicators where the disparity was reversed in the first cluster; however, a substantial reduction in the disparity for Vitamin A supplementation can be seen.

The second cluster of health status indicators similarly highlights rural-urban disparities, but sheds light on how disparities manifest: the sex bias was high for all measures of mortality, but the rural neonatal mortality rate was approaching parity with the urban rate. Bringing these two studies together, we are able to identify where biases entrench (e.g. male child in rural area for under five mortality) and where they diverge (e.g. oral rehydration therapy is more becoming available in rural areas, but less so for female children under five). Such analysis can begin to suggest policy interventions to address ruralurban disparity, whether through community-based information systems, improving maternal and antenatal care through outreach services, institutional deliveries, or non-health measures such as delaying marriages, using contraception or engaging with secondary and higher education (Yared et al, 2013). Focusing only on aggregate and average sex-based analysis will fail to identify key locational differences between urban and rural locations, and unless this data is included, the interactions between the two, and therefore potential layers of disparities, may go unnoticed.

\section{Economic Status}

Living in a rural area does not necessarily equate with increased levels of vulnerability. There are large landholders in rural Ethiopia who have higher income and far better quality of life than those living in urban slums. To identify this form of disparity, one approach is to take economic status into account, and compare the indicators based upon that. The WHO HEAT data provides estimates based on wealth quintile, and for the purposes of this exploratory analysis, we compare the lowest and highest economic quintiles (see Table 5). For the majority of indicators, economic status has increasingly played a stronger differentiating role since 2000 until 2011, whereby higher economic status is associated with improved healthcare coverage or status over time. In sum, as health care coverage and health status improves nationally, it is disproportionately reaching those in the highest economic quintile, and for many health measures the disparity between economic statuses is increasing over time. It is this widening of gaps that poses a real threat to the social justice and inclusion agenda laid out by the SDGs.

Table 5. Economic status disaggregated data for 16 health indicators (red positive, blue negative)

\begin{tabular}{|l|l|c|c|c|}
\hline$\#$ & Indicator & 2000: Wealth Bias & 2005: Wealth bias & 2011: Wealth Bias \\
\hline & Cluster 1 & & & \\
\hline 1 & BCG & +32.3 & +20.5 & +24.5 \\
\hline 2 & DTP3 & +12.6 & +23.6 & +37.6 \\
\hline 3 & FULL & +26.5 & +21.5 & +33.9 \\
\hline 4 & MEA & +34.0 & +27.6 & +34.4 \\
\hline 5 & POL & +22.6 & +19.8 & +30.6 \\
\hline 6 & ORS & +16.7 & +24.4 & +27.3 \\
\hline
\end{tabular}




\begin{tabular}{|l|l|c|c|c|}
\hline 7 & VAS & +15.9 & +16.2 & +12.9 \\
\hline & Cluster 2 & & & \\
\hline$\#$ & Indicator & 2000: Wealth Bias & 2005: Wealth bias & 2011: Wealth Bias \\
\hline 8 & IMR & -1.9 & +19.1 & +31.2 \\
\hline 9 & NMR & -3.7 & +9.0 & +13.1 \\
\hline 10 & U5M & +11.8 & +37.5 & +52.1 \\
\hline 11 & UP3 & +16.0 & +10.5 & +18.6 \\
\hline 12 & UP5 & +13.2 & +11.7 & +20.7 \\
\hline 13 & SP3 & +16.6 & +11.1 & +16.5 \\
\hline 14 & SP5 & +11.6 & +12.5 & +19.7 \\
\hline 15 & WP3 & +3.7 & +5.7 & +9.8 \\
\hline 16 & WP5 & +3.6 & +6.5 & +7.5 \\
\hline
\end{tabular}

Disaggregating the data by sex (Table 3) presented a complex picture, but one wherein disparities were being changed (and sometimes creating different disparities). The rural-urban analysis (Table 4) showed how entrenched rural disparities are, with limited progress occurring over time. Disaggregating health coverage and status by economic statuses shows a different trend: the disparities between the highest and lowest economic status quintiles are increasing for most indicators. This finding may be missed if the differences are aggregated into sex or rural data points, without taking into account the distribution of benefits within female-male or rural-urban categories. The impact of economic status on health outcomes has also been found in other studies and countries (e.g. Kusneniwar et al, 2013). What we emphasize here is that the trends and outcomes are different, and therefore the processes affecting the manifestation of social differentiation are different for each of the domains explored.

It is noteworthy to add that Table 5 compares the lowest and highest quintiles of economic status and while many indicators follow the general trend of higher economic status aligning with greater health coverage and health status, this was not always the case. For example, in 2000 the infant mortality rate is highest for the middle quintile, being significantly higher (141.5) than both the highest quintile (94.9) and the lowest quintile (93.0). In 2000, this was also the case for neonatal morality, under five mortality, underweight prevalence in children under five, wasting in children under three and five as well as polio immunization. These seven indicators demonstrate that being in the lowest economic status quintile does not equate with the poorest health outcomes, and at least for some indicators being in the middle economic status quintile did. Searching for causality is beyond the scope of this paper, but several factors may have potentially contributed to such an outcome. First, emergency service provision can focus on reaching the poorest members of society to reduce mortality, while in the process underserving the relative middle. Second, many pastoralist groups in Ethiopia, such as the Afar, are likely to be counted in the lower wealth quintiles, yet their diets, consisting of maize, milk and meat, derived from their livestock, are often more balanced and nutritious than middle class diets, and could contribute to better health statuses (Fratkin et al., 1999). A third explanation could be cultural, wherein upward economic mobility leads to restrictions on women's work and movement, due to status considerations, a phenomenon visible in countries such as India, with negative implications for health and wellbeing (Dyson and Moore, 1983). However, by 2011, these third quintile trends had all disappeared, and health coverage and status aligned strongly with economic status. During this same period, pastoralist livelihoods, for instance, have experienced increasing pressure, both from recurrent droughts and development interventions, with the Afar mentioned above becoming increasingly reliant upon food aid 
(personal observation, July 2016). In the case of infant mortality in 2011 compared to 2000, the rate for the lowest economic quintile remained stable, whereas for other economic status quintiles the rate improved over the eleven year period, with higher economic status quintiles improving at a faster rate.

\section{Educational Attainment}

Particularly in relation to child health, a great deal of emphasis has been placed upon female education (Asefa, Drewett and Tessema, 2002; Caldwell, 1979; Hobcraft, McDonald and Rutstein, 1984; Kumar and File, 2010; Kusneniwar et al, 2013; Weldearegawi et al, 2015). The WHO HEAT database assesses education status based on the highest level of schooling attained by the mother of the infant or child for which data is presented (no education, primary school, secondary school +). Our analysis compares the disparity between no education and secondary school or greater, and ought to be understood as only one potential way of analyzing the impact of education on the manifestation of vulnerability and opportunity. The results in Table 6 show that educational attainment of mothers has a significant impact on infant and child health coverage as well as health status. There were no exceptions to this.

Table 6. Education status of mother for 16 health indicators (red positive, blue negative)

\begin{tabular}{|l|l|c|c|c|}
\hline$\#$ & Indicator & 2000: Education Bias & 2005: Education bias & 2011: Education Bias \\
\hline & Cluster 1 & & & \\
\hline 1 & BCG & +39.5 & +29.4 & +39.5 \\
\hline 2 & DTP3 & +37.6 & +36.8 & +41.1 \\
\hline 3 & FULL & +34.6 & +24.3 & +36.9 \\
\hline 4 & MEA & +39.6 & +33.4 & +39.5 \\
\hline 5 & POL & +33.0 & +34.0 & +35.2 \\
\hline 6 & ORS & +32.1 & +34.6 & +41.7 \\
\hline 7 & VAS & +22.5 & +20.3 & +16.7 \\
\hline & Cluster 2 & & & $\mathbf{2 0 1 1 :}$ Education Bias \\
\hline$\#$ & Indicator & 2000: Education Bias & 2005: Education bias & +47.0 \\
\hline 8 & IMR & +54.9 & +45.2 & +24.0 \\
\hline 9 & NMR & +36.7 & +19.7 & +83.3 \\
\hline 10 & U5M & +107.2 & +84.5 & +17.8 \\
\hline 11 & UP3 & +18.0 & +22.6 & +22.3 \\
\hline 12 & UP5 & +19.8 & +24.6 & +22.5 \\
\hline 13 & SP3 & +25.0 & +22.5 & +26.6 \\
\hline 14 & SP5 & +22.8 & +23.5 & +8.3 \\
\hline 15 & WP3 & +6.8 & +10.0 & +7.1 \\
\hline 16 & WP5 & +5.5 & +8.9 & \\
\hline
\end{tabular}

It might be assumed that the benefits of female education would arrive at a point of diminishing returns, particularly as the government expands geographic coverage and improves service quality, and thus this inequality will decline over time. For the first cluster, which are more closely linked to service availability and access, this was not the case. Nor was this the case for most of the indicators in the second cluster. Noteworthy, however, is that the impact of expanded access to education will not necessarily, nor immediately, increase female educational attainment. An example of this is that relatively new 
expanded access to education will take a generation to be expressed in the data on mothers. A second barrier is that there continue to be gender disparities affecting educational attainment - including lower enrolment of girls and more absence, as well as inequalities of quality (Delelegn, 2007; Molla, 2013; Molla and Cuthbert, 2014; Rose, 2003). Despite these challenges, educational attainment of mothers cannot be under-valued. This is particularly evident because the inequalities emerging from a lack of access to education are, across all indicators and across all time, greater than that of the male-female, rural-urban or economic-status divides. The result is a compounding of the challenges related to child health due to a host of gendered challenges on educational access, attainment and quality.

\section{Regional-state (geopolitical location)}

The rural-urban question is essentially one about the impact of geospatial location, and the availability of infrastructure, services and goods in relation to that. In Ethiopia, there is good reason to investigate the impact of social differentiation based on ethnic and political lines (Berhanu and Poulton, 2014; Cochrane and Tamiru, 2016; De Waal, 2015). The post-1991 Ethiopia regional-state configuration provides one proxy means to explore this because at least five of the nine regional states were drawn largely along ethnic lines (see Table 7). An analysis of health coverage and status based on regional-state then goes beyond the rural-urban question of location, and begins to assess the degree to which ethnicity is shaping inclusion and exclusion through its influence on power and political decision making. This supports Nancy Fraser's call to explore not just economic differentiation and need for resource redistribution in the attainment of social justice, but equally to pay attention to the socio-cultural domain of recognition and the political domain of representation (2009).

Table 7. Ethiopian regional-states and Ethnicity (based on CSA, 2007)

\begin{tabular}{|l|l|l|}
\hline Regional-State & Main Ethnic Group & \% of population \\
\hline Afar & Afar & 90.0 \\
\hline Amhara & Amhara & 91.5 \\
\hline Oromia & Oromo & 87.8 \\
\hline Somali & Somali & 97.2 \\
\hline Tigray & Tigray & 96.6 \\
\hline
\end{tabular}

There are three exceptions to ethnic homogeneity of regional-states: Benishangul-Gumuz, Gambella and the Southern Nations, Nationalities and Peoples' (SNNP) regional-states, wherein ethnic diversity exists. All three have, however, experienced long-term marginalization, and have been classified by the Government of Ethiopia as part of the "Emerging Regions" due to their relative lower performance on human development indicators. Thus, ethnic diversity alone ought not to be understood as the reason for disparities between regional-states, but also the extent to which the regional-states have had the political power or demographics to demand inclusion, or the resources to require it. Political mobilisation around particular social identities, whether gender, ethnicity or any other, is a means to legitimising claims, and securing investments from the state (Fraser, 1989). In the last decade, major investments have been made in Benishangul-Gumuz and Gambella regional-states, and thus a greater role of the government has manifested itself since that time. As a measure of political, as opposed to ethnic, prioritization or marginalization, we have included these regional-states for analysis. 
All city administrations have been excluded from this analysis. We have also excluded Harari regionalstate as its population is small relative to the others, the majority of which is urban, and is thus more akin to a city administration than a regional-state. For the analysis, we compare each regional-state against the national figure, as opposed to comparing to other regional-states. This is a different approach than the previous analyses, which compared the disparity between statuses. The objective remains the same, to assess disparities, however because the data points are not directly comparable in the way that male-female, rural-urban, economic statuses and educational attainment are, we felt this data was best presented as a disparity against the national average.

As there are sixteen health indicators and eight regional-states, one example indicator is presented from each cluster to explore the extent of geopolitical disparities. The selection of both example indicators was purposeful. We selected the indicator with the highest coverage from cluster one, BCG coverage, and the highest rate of the non-mortality indicators (the mortality indicators did not have complete data for all regions) from cluster two, stunting prevalence for children under five years of age. In order to align demographic and health indicator data, we have used the 2007 national census data (the most recent national census) to analyze the proportion of ethnicity and rural residents with the 2005 WHO HEAT data set. These two data sets do not perfectly align, but provide the best option available. We do not present data from 2000 and 2011 because analyses over time are challenged by a lack of annual data on population growth, urbanization and ethnicity beyond projections. As the objective of this paper is to explore domains of social differentiation, and not to exhaust all manifestations of disparities within each domain, these example indicators serve the purpose of this article. Future comprehensive studies about infant and child health disparities in Ethiopia can, and should, analyze regional-state disparities in greater detail than what is presented within these two example indicators. It is also noteworthy to add that these two examples are not necessarily representative of the trends of their respective indicator clusters.

There are a number of factors that affect this geopolitical analysis, two of the most prominent are the urban bias and demographics. In order to compare the regional-states in recognition of these factors, Table 8 presents the regional-state divergence from the national immunization coverage rate, as well as the population and percentage of the population that is rural. What is evident in the results is that regional-state disparities are significant, particularly because this is an example of a service provided by the government. Amhara and Oromia regional-states have similarly high populations with the same percentage being rural, but Oromia has a (moderately) lower coverage rate. Somali and Afar regionalstates, however, were significantly lower than the national average, and severely under-served. Tigray, on the other hand, has the highest immunization coverage. In comparison, Somali regional-state has a similar population size and a comparable rural population rate to Tigray, however there is more than a 60 percentage point difference between the two regional-states. Without suggesting causation, but for contextualization: Tigray is the home state of the dominant ethnic group of the federal government, while both Afar and Somali regional-states have long expressed their exclusion and marginalization.

Table 8. Example indicator from cluster 1 (BCG coverage) and cluster 2 (SP5), by regional-state

\begin{tabular}{|l|l|l|l|l|}
\hline Regional State & $\begin{array}{l}\text { BCG coverage +/- } \\
\text { from national, 2005 }\end{array}$ & $\begin{array}{l}\text { SP5 +/- from } \\
\text { national, 2005 }\end{array}$ & $\begin{array}{l}\text { Population } \\
\text { (CSA, 2007) }\end{array}$ & $\begin{array}{l}\text { \% rural (CSA, } \\
\text { 2007) }\end{array}$ \\
\hline Afar & -32.8 & +9.7 & $1,390,273$ & 86.7 \\
\hline Amhara & +1.8 & -12.8 & $17,221,976$ & 87.7 \\
\hline
\end{tabular}




\begin{tabular}{|l|l|l|l|l|}
\hline Benishangul-Gumuz & -6.9 & +6.6 & 784,345 & 86.5 \\
\hline Gambella & -11.1 & +12.0 & 307,096 & 74.6 \\
\hline Oromia & -2.5 & +6.6 & $26,993,933$ & 87.7 \\
\hline SNNP & +3.8 & -3.7 & $14,929,548$ & 90.0 \\
\hline Somali & -43.4 & +0.6 & $4,445,219$ & 86.0 \\
\hline Tigray & +17.0 & +3.8 & $4,316,988$ & 80.5 \\
\hline
\end{tabular}

The example indicator of the second cluster, stunting prevalence for children under the age of five, differs from the immunization example in that it is less reflective of government activity, and more representative of the broader context, of which governmental roles are an important, though only a part. In considering what might make a household vulnerable to poverty in Ethiopia, Husmann (2016) analyzes diverse spheres of life: economics, demography, land scape and location, behavior and quality of life, ecosystems and natural resources, infrastructure, public services and institutions, population and ethnicity. Childhood rates of mortality, underweight, stunting and wasting are reflective of these diverse factors, of which the government has direct control or influence over a subset. Thus, in analyzing regional-state disparities for stunting prevalence, the result is less geopolitical directly, but remains geopolitical to the extent that the government needs to ensure that all people, regardless of where they live, have a basic set of rights protected, including sufficient food to prevent childhood stunting due to malnutrition. The disparities of stunting are not as wide as immunization coverage, and importantly, they are not the same (Table 8). The regional-state with the lowest stunting prevalence is Gambella, whereas Amhara regional-state had the highest stunting prevalence rate. Also of note is that the highest preforming BCG immunization coverage, Tigray regional-state, was only moderately better than the national rate for stunting prevalence, while Somali regional-state was slightly above the national average for stunting prevalence and Afar regional-state well above the national average, despite being severely under-served for BCG immunization coverage. This could, as suggested earlier, be a result of Afar culture, livelihoods and lifestyles.

\section{Layers of vulnerability}

The WHO HEAT data sets enable analyses of several domains of social differentiation that affect health related indicators in Ethiopia. In analyzing these sixteen indicators for infant and child health coverage and health status, we are fully cognizant that many other important differences influence and interact with health coverage and health status. For example, numerous studies demonstrate that the age of a mother at the time of her giving birth impacts infant and child health (Weldearegawi et al, 2015), so too do improved hygiene and sanitation (Kusneniwar et al, 2013) and birth order (Finlay, Ozaltin and Canning, 2011; Kumar and File, 2010). Yet, our objective was not a comprehensive analysis of what the drivers of health coverage and health status are. Rather, we set out to explore manifestations of disparity, using health indicators as a means to do so.

One of the challenges of a narrow focus on sex disaggregation for gender analysis, is that while important, we may miss or under-value the importance of other factors, and furthermore, we may miss or undervalue the impact of multiple layers of intersecting inequalities. For example, based on the results analyzed in this paper, disparities will be multiplied for the poorest members of society living in rural areas, or male infants living in Somali regional-state who have a mother who has not had the 
chance to attend school. Taking a systems approach enables us to see how disparities might interact. The collective impacts are not always compounding negatives, such as the lower rates of stunting in SNNP despite lower immunization coverage. Importantly, however, in the leave no one behind agenda of the SDGs, we need to better understand the layers of disparity that result in multiplied vulnerabilities. Rather than positing the modern versus the traditional, the formal versus the informal, the educated versus the non-literate, such analysis can contribute to identifying and strengthening positive health practices, whether formal or informal (Sen, 2006).

Husmann (2016) provides an innovative example of how marginalization can be analyzed in Ethiopia by mapping layers of factors using geographic information system (GIS) software in order to identify the 'hotspot' areas of greatest marginalization. The results of that layering identify Afar regional-state, and parts of SNNP and Amhara, as particularly marginalized, through multiple dimensions, while Somali and SNNP regional-states experience the most severe marginalization for some of the dimensions. A limitation of Husmann's (2016) work is that it is based upon geographic space, providing a literal bird's eye view of the landscape of marginalization. What is also required is multidimensional analyses, which dig deeper into demographic, socio-cultural, economic and political factors that intensify marginality within particular contexts (such as urban slums). Limitations aside, the work of Husmann is in line with the advances of the Multidimensional Poverty Index (Alkire and Robles, 2015). Thinking about disparities, vulnerability and poverty as occurring in multi-dimensional and multiplying ways, however, has not yet transformed the expectations and demands of research donors. This needs an emphasis on social inequality in all its dimensions - economic, political and cultural - and ways of addressing it.

\section{Discussion}

Using the example of infant and child health in Ethiopia, we have shown how sex-based disparities for health coverage have changed over the past 15 years, but how health status has been relatively stable. In fact, male children under the age of 5 continue to show higher levels of wasting and stunting and remain more prone to mortality than female children. The findings of the rural-urban disaggregation confirm the entrenched disparities experienced by people living in rural areas. The analysis of economic status quintiles raised interesting questions - ones well beyond what this paper was able to answer about how and why changes have occurred and how disparities between quintiles manifest. Geopolitical differences within the nation also appear to work in different directions, pointing to the importance of politics and political mobilisation in ensuring rights. As Amartya Sen (1999) has argued, freedom of speech and democratic space for articulating needs and claiming rights, remain central to the process of development, but also social justice and the 'leave no one behind' agenda of the SDGs.

Educational attainment of mothers is one of the most significant indicators in terms of both access to health services and the health status of children. In fact, female education is one area, where investments seem to have paid off in multiple ways, whether through improving children's health and wellbeing, or enhancing women's own agency within and beyond the household (Lloyd, 2013). The five domains analysed in this paper (male-female, rural-urban, economic status, education attainment, geopolitics) raise key questions about the reproduction and intensification of inequality: low economic status in rural areas within households of low educational attainment located in neglected regionalstates. This is the severe marginalization identified by Husmann (2016), it is not necessarily marginalization across every domain, but deep and disproportionate disparities for certain key domains, with multiplier effects on the overall quality of life and wellbeing. While beyond the scope of this paper, 
it would be interesting to map such severe marginalisation with regions of conflict and discontent within the country; when pushed to the wall, people have little option but to protest.

Our point was not to suggest that one manifestation is more important than another by comparing the extent of disparities. The point is that focusing too strongly upon only one potential domain of social differentiation may reduce our collective ability to understand the diverse causes, manifestations and impacts of social inequalities. Understanding disparities and marginalization based on sex and gender is important, and must translate into more informed policy, programs and practice. However, to be meaningful in addressing the rising threat of deepening inequalities, we also need data and analyses that examine the interaction between different forms of difference, and the intensification of 'injustices', to use Nancy Fraser's term (1989), as people experience multiple layers of marginalization, discrimination and vulnerability. Such an intersectional understanding of gender relations is now growing within the academic field of development studies, led by research in gender and development (Molyneux and Razavi, 2005; Rao, 2014, Walby, 2007). The need to build broad-based alliances has also been acknowledged by feminist movements globally (Cornwall and Edwards, 2015). Research donors in particular, as they demand for greater focus upon sex and gender, should not lose sight of the larger objective in promoting research that reduces vulnerabilities and increases inclusion; this in fact is central to protecting gender rights. Doing so requires us to take a broad perspective on social inequalities and its structural drivers. The SDGs and the 'Leave No One Behind' agenda demand it.

\section{Works Cited}

ACIAR. 2011. Annual Operational Plan 2011-12. Australia Centre for International Agricultural Research: Canberra.

Alkire, S. and Robles, G. 2015. Multidimensional Poverty Index - 2015: Brief Methodological Note and Results. Oxford Poverty and Human Development Initiative, University of Oxford: Oxford.

Asefa, M., Drewett, R. and Tessema, F. 2002. A Birth Cohort Study in South West Ethiopia to Identify Factors Associated with Infant Mortality that are Amenable for Intervention. Ethiopian Journal of Health Development 14: 161-168.

Bekele, S. 2017. The Accuracy of Demographic Data in the Ethiopian Censuses. Eastern Africa Social Science Research Review 33: 15-38.

Berhanu, K. and Poulton, C. 2014. The Political Economy of Agricultural Extension Policy in Ethiopia: Economic Growth and Political Control. Development Policy Review 32(2): s197-s213.

Boserup, E. 1970. Women's Role in Economic Development. New York: St Martin's Press.

Caldwell, J. C. 1979. Education as a Factor in Mortality Decline: An Examination of Nigerian Data. Population Studies 33: 395-413.

Carletto, C., Jollife, D. and Banerjee, R. 2015. From Tragedy to Renaissance: Improving Agricultural Data for Better Policies. Journal of Development Studies 51: 133-148.

CGIAR. 2017. The Gender Network. https://gender.cgiar.org/the-gender-network/ 
Chambers, R. 1983. Rural Development: Putting the Last First. Longman: London.

Chambers, R. 1997. Whose Reality Counts? Putting the First Last. ITDG Publishing: London.

Chambers, R. 2006. Poverty Unperceived: Traps, Biases and Agenda, Working Paper 270. Institute of Development Studies: Brighton.

Cochrane, L. and Tamiru, Y. 2016. Ethiopia's Productive Safety Net Program: Politics, Power and Practice. Journal of International Development 28(5): 649-665.

Cochrane, L. and Thornton, A. 2017. The Geography of Development Studies: Leaving No One Behind. Forum for Development Studies DOI: https://doi.org/10.1080/08039410.2017.1345786.

Cochrane, L. and Yeshtila W. B. 2018. Average Crop Yield (2002-2017) in Ethiopia: Trends at National, Regional and Zonal Levels. Data in Brief.

Collins. P. H. 2010. The new politics of community. American Sociological Review. 75(1): 7-30.

Cornwall, A and Edwards, J. 2015. Introduction: Beijing+20 - Where now for gender equality? IDS Bulletin. 46(4): 1-8.

Crenshaw, K. 1989. Demarginalizing the intersection of race and sex: A black feminist critique of antidiscrimination doctrine, feminist theory and antiracist politics. University of Chicago Legal Forum. 1989(1): Article 8 pp. 139-167.

CSA. 1994. Population and Housing Census of 1994. Central Statistics Agency: Addis Ababa.

CSA. 2007. Population and Housing Census of 2007. Central Statistics Agency: Addis Ababa.

De Waal, A. 2015. The Real Politics of the Horn of Africa: Money, War and the Business of Power. Polity Press: Malden.

Delelegn, A. 2007. Intra-household Gender-bias in Child Educational Spending in Rural Ethiopia: Panel Evidence. Ethiopian Journal of Economics XVI(2): 1-38.

Deribew, A., Tessema, F. and Girma, B. 2007. Determinants of Under-five Mortality in Gilgel Gibe Field Research Center, Southwest Ethiopia. Ethiopian Journal of Health Development 21: 117-124.

DFID. 2008. The Gender Manual: A Practical Guide. Department for International Development: London.

Duchesne, A., Tannenbaum, C. and Einstein, G. 2017. Funding Agency Mechanisms to Increase Sex and Gender Analysis. The Lancet 389(10070): 699.

Dyson, T. and M. Moore. 1983. On Kinship Structure, Female Autonomy, and Demographic Behavior in India. Population and Development Review. 9(1): 35-60.

Finlay, J. E., Ozaltin, E. and Canning, D. 2011. The Association of Maternal Age with Infant Mortality, Child Anthropometric Failure, Diarrhoea and Anaemia for First Births: Evidence from 55 Low- and Middle-Income Countries. BMJ Open 1: e000226.

Fraser, N. 1989. Unruly Practices. Cambridge: Polity Press. 
Fraser, N. 2009. Scales of Justice: Reimagining political space in a globalizing world. New York. Columbia University Press.

Fratkin, E., Nathan, M.A and E. A. Roth (1999) Health Consequences of Pastoral Sedenterization among Rendille of Northern Kenya. In: Anderson, D. M. and V. Broch-Due (eds) The Poor are Not Us: Poverty and Pastoralism in Eastern Africa. Oxford: James Currey.

Gates Foundation. 2017. Creating Gender-responsive Agricultural Development Programs: http://www.gatesfoundation.org/What-We-Do/Global-Development/AgriculturalDevelopment/Creating-Gender-Responsive-Agricultural-Development-Programs

Hobcraft, J. N., McDonald, J. W. and Rutstein, S. O. 1984. Socio-Economic Factors in Infant and Child Mortality: A Cross-national Comparison. Population Studies 38: 193-223.

Hosseinpoor, A. R., Nambiar, D., Schlotheuber, A., Reidpath, D. and Ross, Z. 2016. Health Equity Assessment Toolkit (HEAT): Software for Exploring and Comparing Health Inequalities in Countries. BMC Medical Research Methodology 16: 141.

Husmann, C. 2016. Marginality as a Root Cause of Poverty: Identifying Marginality Hotspots in Ethiopia. World Development 78: 420-435.

Jerven, M. 2013. Poor Numbers: How We are Misled by African Development Statistics and What to Do About it. Ithaca: Cornell University Press.

Kumar, P. P. and File, G. 2010. Infant and Child Mortality in Ethiopia: A Statistical Analysis Approach. Ethiopian Journal of Education and Sciences 5(2): 51-57.

Kusneniwar, G. N., Mishra, A. K., Balasubramanian, K. and Reddy, P. S. 2013. Determinants of Infant Mortality in a Development Region in Rural Andhra Pradesh. National Journal of Integrated Research in Medicine 4(4): 20-26.

Lloyd, C. B. 2013. Education for Girls: Alternate Pathways for Girls' Empowerment. Paper commissioned by Girl Hub, a strategic partnership between Nike Foundation and the UK Department for International Development. London.

Merry, S. E. 2011. Measuring the World: Indicators, human rights, and global governance. Current Anthropology. 52(3): 583-595.

Molla, T. 2013. Higher Education Policy Reform in Ethiopia: The Representation of the Problem of Gender Inequality. Higher Education Policy 26(2): 193-215.

Molla, T. and Cuthbert, D. 2014. Qualitative Inequality: Experiences of Women in Ethiopian Higher Education. Gender and Education 26(7): 759-775.

Molyneux, M. and Razavi, S. 2005. Beijing Plus Ten: An Ambivalent Record on Gender Justice. Development and Change 36(6): 983-1010.

Morchain, C., Prati, G., Kelsey, F. and Ravon, L. 2015. What if Gender became an Essential, Standard Element of Vulnerability Assessments? Gender \& Development 23(3): 481-496. 
Njuki, J. and Sanginga, P. C. (Eds) 2013. Women, Livestock Ownership and Markets: Bridging the Gender Gap in Eastern and Southern Africa. International Development Research Centre: Ottawa.

Ostebo, M. T., Cogburn, M. D. and Mandani, A. S. 2017. The Silencing of Political Context in Health Research in Ethiopia: Why it Should be a Concern. Health and Policy Planning DOI: 10.1093/heapol/czx150

Piketty, T. 2014. Capital in the Twenty-First Century [translated by A. Goldhammer]. Cambridge: Harvard University Press.

Pongou, R. 2013. Why is Infant Mortality Higher in Boys than Girls? A New Hypothesis Based on Preconception Environment and Evidence from a Large Sample of Twins. Demography 50(2): 421444.

Pongou, R. 2015. Sex Differences in Early-age Mortality: The Preconception Origins Hypothesis. Demography 52: 2053-2056.

Rao, N. 2014. Caste, Kinship and Life-course: Rethinking Women's Work and Agency in Rural South India. Feminist Economics, 20(4): 78-102.

Rao, N. (2017). Assets, Agency and Legitimacy: Towards a Relational Understanding of Gender Equality Policy and Practice. World Development. 95: 43-54.

Rao, N. 2018 (forthcoming). Global Agendas, Local Norms: Mobilizing around Unpaid Care Work in Asia. Development and Change. 49(3).

Razavi, S. and Miller, C. 1995. From WID to GAD: Conceptual Shifts in the Women and Development Discourse, UNRISD Occasional Paper \#1, Geneva.

Rose, P. 2003. Can Gender Equality in Education be Attained? Evidence from Ethiopia. United Nations Educational, Scientific and Cultural Organization, 2004/ED/EFA/MRT/PI/64.

Sen, A. 1999. Development as Freedom. Oxford. Oxford University Press.

Sen, G. 2006. Informal Institutions and Gender Equality. Paper presented at the OECD International Seminar on 'Informal Institutions and Development: What do we know and what can we do?' December 11-12, Paris.

Stiglitz, J. E. 2013. The price of inequality. London. Penguin.

Sweetman, C. (Ed.) 2001. Gender, Development and Health. Oxfam: Oxford.

UN, 2016: Leaving No One Behind. http://unstats.un.org/sdgs/report/2016/leaving-no-onebehind

UNDP, 2016 Helen Clark: Speech on 'A Commitment to Leave No One Behind: Equity in the SDGs'. www.undp.org/content/undp/en/home/presscenter/speeches/2016/06/04/helenclark-leave-noone-behind-equity-in-the-sdgs-save-the-children-annual-meeting.html

Walby, S. 2007. Complexity theory, systems theory, and multiple intersecting social inequalities. Philosophy of the Social Sciences. 37: 449-70. 
Weldearegawi, B., Melaku, Y. A., Abera, S. F., Ashebir, Y., Haile, F., Mulugeta, A., Eshetu, F. and Spigt, M. 2015. Infant Mortality and Causes of Infant Deaths in Rural Ethiopia: A Population-based Cohort of 3684 Births. BMC Public Health 15: 770.

WHO. 2016. Health Equity Assessment Toolkit Version 1.0. World Health Organization: Geneva.

WHO. 2017. Ethiopia: Analytical Summary. http://www.aho.afro.who.int/profiles information/index.php/Ethiopia:Analytical summary Health Status and Trends

Yared, M., Tensou, B., Telake, D. S., Degefie, T., and Bekele, A. 2013. Neonatal mortality in Ethiopia: trends and determinants. BMC Public Health. 13: 483. doi: 10.1186/1471-2458-13-483 